\title{
INTRODUCTION: ACTION IN CHINESE PHILOSOPHY
}

Philosophy of action deals with questions about the nature of action and action-related concepts such as intention, reasons, and motivation. With this special issue, we hope to contribute to the Journal of Chinese Philosophy's mission of bringing insights gleaned from Chinese philosophy to bear on important issues in contemporary philosophy.

A number of articles in this volume challenge or otherwise complicate previous accounts of differences between Chinese and Western philosophical accounts of action. In his 2009 paper "Action and Agency in Chinese Thought," Chris Fraser argues that, in contrast to Western accounts that emphasize deliberation and rational decisionmaking, resulting in a belief-desire model of agency, pre-Qin conceptions of agency are "concerned primarily with abilities, habits, and the skill-like performance of familiar patterns of activity." ${ }^{1}$ Erica Brindley's article in this collection, entitled "Authoring Non-Action in Early China," similarly notes that "a few early Chinese discourse on action outline normative agency precisely by negating and having an agent abandon his or her ostensible position as a rational agent." However, Brindley goes on to highlight important similarities between Chinese and Western accounts, arguing that both emphasize individual choice, purpose, and desire. John Ramsey, in his paper "Wisdom, Agency, and the Role of Reasons in Mengzi," also challenges the contrast between deliberation-based Western models of agency and Chinese performance-based ones, arguing that the Mengzi at least includes both models. Susan Blake argues further in her paper, "Agency, Non-Action, and Desire in the Laozi," that deliberation is a necessary feature of the Daoist sage.

Another set of papers discusses the connection between knowledge and action in the Chinese philosophical tradition. In his paper, "To Really See the Little Things: Sage Knowledge in Action," Barry Allen expresses this connection as follows:

TIMOTHY CONNOLLY, Associate Professor and Chair, Philosophy and Religious Studies Department, East Stroudsburg University. Specialties: ancient Greek philosophy, classical Chinese philosophy. E-mail: tconnolly@po-box.esu.edu

Journal of Chinese Philosophy 42:3-4 (September-December 2015) 265-266 (C) 2017 Journal of Chinese Philosophy 
Knowledge is not wise until it enhances action. Without action the knowledge remains in process and might be interrupted and fail to form; and if action turns out badly, then it never was knowledge at all. This unity of knowledge and action (zhi xing he $y i$ 知行合一) is associated with the name of Wang Yangming, but I wonder which Chinese thinker would not approve it?

In particular, Allen's paper discusses the "subtle perception" of sage knowledge, and how this knowledge is connected with sage's "wuwei effectiveness." In making this link, Allen argues for an interpretation of wuwei as "intensive effortlessness." Sam Cocks' paper, "Wang Yangming on Spontaneous Action, Mind as Mirror, and Personal Depth," focuses on the Neo-Confucian philosopher's connection between "innate knowing" (liang zhi 良知) and spontaneous action, which Cocks develops through an investigation of Wang's use of the mind-as-mirror metaphor. Finally, Youngmin Kim's paper, entitled "Moral Action in Zhan Ruoshui's Philosophical Anthropology," explores Zhan's idea of "realizing the principle of Heaven in every situation” (suichu tiren tianli 隨處體認天理), a competitor to Wang's notion of the unity of knowledge and action.

This project originally began as a session at the Pacific Division meeting of the American Philosophical Association in March 2013, organized at the suggestion of the Journal's editors.

For the present volume, I would like to acknowledge the help and hard work of Professor Chung-ying Cheng and Dr. Linyu Gu, and also of our contributors and reviewers.

EAST STROUDSBURG UNIVERSITY

East Stroudsburg, Pennsylvania

\section{ENDNOTE}

1. Chris Fraser, "Action and Agency in Chinese Thought," Journal of Chinese Philosophy and Culture 5 (2009): 217-39, 217. 